\title{
LOS PROBLEMAS DE LA ADMINISTRACIÓN FISCAL EN LOS ÚLTIMOS AÑOS DE LA NUEVA ESPAÑA, 1810-1821
}

\section{PROBLEMS WITH FISCAL ADMINISTRATION IN THE LAST YEARS OF NEW SPAIN, 1810-1821}

\author{
LUIS JÁUREGUI \\ Instituto de Investigaciones Dr. José María Luis Mora, México \\ ljauregui@mora.edu.mx
}

https://doi.org/10.36105/iut.2021n33.04

Recibido: 05/08/2021

Aceptado: 30/08/2021

\section{RESUMEN}

Este ensayo pretende hacer una descripción de la manera como, debido a los once años de guerra de independencia, la administración fiscal del virreinato de Nueva España se desarticuló, perdió rutinas y colmó de trabajo al funcionariado fiscal que permaneció al frente de las oficinas de la hacienda pública. La problemática administrativa se acentuó también por una contabilidad compleja y en ocasiones caótica, así como por la aparición de los intermediarios liberales - como los ayuntamientos y las diputaciones provinciales - en la estructura organizativa de los impuestos/gastos del erario novohispano. Se han realizado otros trabajos sobre la administración fiscal del periodo. Para estos, sin embargo, se ha hecho uso de leyes, reglamentos y circulares, lo que dificulta observar el fenómeno real. Por lo mismo, aquí se recurre a casos específicos de la práctica administrativo-fiscal con la idea de que sólo mediante la observación de éstos, que nunca son todos ni los más representativos, es que podemos atisbar la desarticulación de una lógica de funcionamiento administrativo. 
Palabras clave:

Nueva España, guerras de independencia, impuestos, administración pública, contabilidad.

\section{Abstract:}

This essay gives a description of the deterioration of New Spain's fiscal administration during the wars of independence. In this process different aspects are contemplated: loss of office articulation, routines, and more work for the public finance bureaucrat. There was also the problem of a very complex and somewhat chaotic accounting as well as the implementation of liberal instances like provincial deputations and city councils with a definite say in tax implementation and administration. There is current historiography that addresses these issues; still in these instances it is difficult to observe the real phenomenon because of the use of printed laws, instructions, and general notices as main sources of analysis. What this paper proposes is the exploration of actual cases of fiscal administration. These, however, will never be all nor the most typical, but give a general view of the New Spain's administrative dislocation during the wars of independence.

Keywords:

New Spain, wars of independence, taxes, public administration, accounting.

Las luchas novohispanas para conseguir su independencia de España transcurrieron durante once largos años. En ese lapso, la monarquía española se enfrentó a una lucha insurgente que recibió y aplicó a su modo los principios liberales dictados desde la España invadida. Cuando ésta se despojó del yugo napoleónico y con un movimiento insurgente amenazando la tranquilidad del virreinato, quedó restablecido durante seis años, un régimen absolutista que ya no tenía cabida ni siquiera en España. Con la restitución de la constitución liberal a mediados de 1820, una parte del ejército que anteriormente había luchado contra la insurgencia se organizó para lograr la independencia de la muy lejana metrópoli peninsular.

Las autoridades de la Nueva España no estaban preparadas para enfrentar lo que primero fue un levantamiento popular bastante violento. Hasta antes de su debilitamiento con el golpe de estado dado a la autoridad virreinal en 1808, el aparato burocrático operaba razonablemente bien. Sin embargo, la magnitud del levantamiento de Hidalgo en septiembre de 1810 golpeó con fuerza la maquinaria administrativa que financiaba los trabajos del virreinato tales como el hecho de ser una subtesorería de la corona en la zona del Gran Caribe y Filipinas, así como la defensa de una gran frontera norteña, en contra del creciente dominio norteamericano.

Este ensayo pretende hacer una descripción de la manera en la cual la administración fiscal del virreinato se desarticuló, perdió rutinas e incrementó de 
trabajo al funcionariado fiscal que permaneció al frente de las oficinas de la hacienda pública de Nueva España. La problemática administrativa se acentuó debido también a una contabilidad difícil y caótica, así como a la aparición de otros intermediarios - las diputaciones provinciales y los ayuntamientos - en la estructura organizativa de los impuestos/gastos del Erario novohispano.

La última administración financiera del último virreinato se caracterizó por su militarización, el desbaratamiento de rutinas y la fragmentación de un conocimiento acumulado durante muchos años. Por la vía de leyes, reglamentos y circulares es difícil observar este fenómeno, toda vez que estos documentos muestran el "deber ser" de la administración. Es sólo mediante la observación de casos específicos, que, desafortunadamente, nunca son todos ni los más representativos, que podemos atisbar la desarticulación de una lógica de funcionamiento. De aquí suponemos que se origina una parte de la problemática fiscal de las primeras décadas del México independiente.

\section{LOS INTENDENTES, EL CAMBIO DE LAS RUTINAS Y EL AUMENTO DE TAREAS}

A finales de 1808, tal vez con la esperanza de que la situación mejorara y con la idea de que el rey iba a regresar y que las cosas volverían a ser como antes, la Junta Central dispuso una serie de cambios administrativos en los territorios americanos que se antojaban difíciles de lograr. En general, la Junta se proponía conocer el monto de la deuda y de las recaudaciones; tenía la intención de ahorrar en todos los ramos de la administración, cortar los abusos de los funcionarios, simplificar el sistema tributario y eliminar los empleos inútiles. Una medida importante fue la de regresar la jurisdicción coactiva a los oficiales de la Real Hacienda que la Ordenanza de Intendentes de 1786 había otorgado exclusivamente a los intendentes y subdelegados. Tal parece que las autoridades peninsulares deseaban volver a la normalidad y evitar el conjunto de situaciones anómalas que se habían presentado con motivo de las exacciones extraordinarias de 1808 y $1809 .{ }^{1}$

La actitud de la Junta Central no era del todo disparatada. Si como lo afirma Hobsbawm, la autoridad se destruye por la vía de sus símbolos, y el símbolo más elocuente de la pérdida de autoridad habían sido precisamente las abdicaciones de Bayona, lógico es pensar que la Junta Central deseaba restañar, siquiera nada más por vía de un decreto, la autoridad de la monarquía española.

La urgencia de recursos era, empero, más importante que los símbolos. En el verano de 1809 la Junta Central comprometía los recursos de las tesorerías novohispanas para que éstas pagaran a Inglaterra el préstamo otorgado por esta nación a la resistencia en contra de los franceses. En agosto de ese año, por vía de un bando, el virrey Lizana autorizaba al tribunal de minería y a los consulados de México, Veracruz y Guadalajara a solicitar recursos "por todos los medios posibles"; como hipoteca ofreció los recursos generados por la renta del tabaco

JÁUREGUI, Luis, La real hacienda, 1999, pp. 232-233. 
que pagaría $6 \%$ anual por estos dineros. El depósito, la correspondiente entrega de escrituras, así como los propios réditos se harían a través de las tesorerías provinciales que, según apunta el bando, actuarían al paralelo de los consulados de comerciantes y el tribunal de minería. ${ }^{2}$

Los resultados administrativos del bando de Lizana muestran lo siguiente: por una parte, se delegaba en las cajas provinciales una función - emitir papeles de deuda interna - que anteriormente sólo correspondía a la tesorería general de ejército y real hacienda. Además, otorgar igual función a los consulados de comerciantes y al tribunal de minería sugiere que las fuerzas centrífugas que se contuvieron durante los últimos años del siglo XVIII poco a poco se fueron vigorizando debido en parte al cambio de estructuras sociales en las regiones. La búsqueda del socorro a la península obligó al mando virreinal a echar mano de los consulados (dos de ellos creados apenas en 1795) y del tribunal de minería.

Ahora bien, es posible que la aplicación de esta medida respondiera a un hecho que se venía dando desde finales del siglo XVIII y que está relacionado con el sistema intendencial. Según Horst Pietschmann, las intendencias tuvieron dos efectos, uno positivo y otro negativo. Por una parte, su labor financiera facilitó la formación de una organización burocrática "según los lineamientos modernos [...] un cimiento [...] sobre el que se [pudo] fundar un organismo estatal independiente". Por el otro, en lo financiero, las intendencias prácticamente operaron sólo en las ciudades capitales de las provincias pues no podían depender de los subdelegados en los distritos, toda vez que en algunas partes estos funcionarios eran mal pagados o no sabían desempeñar su trabajo. ${ }^{3}$ Pero ni los subdelegados ni los intendentes fueron culpables de esta situación. Según Pietschmann la ineficacia de la administración distrital se explica por la sobrecarga de trabajos burocráticos y, más importante por "la insuficiente organización de la administración central virreinal (en especial después de que se suprimió la superintendencia independiente". ${ }^{4} \mathrm{Al}$ respecto, el segundo virrey Revillagigedo externó reiteradamente su queja a la corte de Madrid en el sentido de que ni la Audiencia ni el Tribunal de Cuentas cumplían con sus tareas y se lamentaba de la pereza generalizada de los funcionarios. Y si esa fue la situación durante la notable gestión virreinal de Revillagigedo ¿qué se podía esperar de los virreyes que le sucedieron cuyos gobiernos ciertamente dieron resultados bastante mediocres? ${ }^{5}$

En materia de autoridad, en los primeros años del siglo XIX los intendentes fueron vistos, en el mejor de los casos, como alcaldes mayores con atribuciones ampliadas. Desde el gobierno superior, las autoridades virreinales consistentemente se entrometieron en los asuntos que dependían exclusivamente según la ley a

2 El tribunal de minería no aportó a esta convocatoria; ya había otorgado a la corona demasiados préstamos y donativos que fueron ruinosos. MÉNDez PÉREz, Juan Ramón, “La quiebra del Tribunal”, 2012, pp. 59-60. PietschmanN, Horst, Las reformas borbónicas, 1996 [1972], pp. 288 ss.

4 Ibidem, p. 295. La ordenanza de intendentes de 1786 separaba la figura del superintendente subdelegado de real hacienda de la del virrey. Esta situación era políticamente inviable, de manera que pocos meses después (1788) el virrey volvió a detentar ambos cargos. Véase ARNOLD, Linda, La secretaría de cámara, 1979.

5 Pietschmann, Horst, Las reformas borbónicas, 1996 [1972], loc cit. 
estos jefes provinciales. ${ }^{6}$ Ante tales condiciones, poco se podía esperar de los intendentes en materia de colectación de préstamos y donativos urgentes para el apoyo a la península. A manera de ejemplo, en octubre de 1809, el obispo de Nuevo León otorgó un préstamo de 50 mil pesos a la corona. El prelado depositó este dinero en la tesorería de Saltillo; ésta le otorgó a cambio una escritura de préstamo que, meses después, fue desautorizada por el intendente de San Luis Potosí. El obispo comunicó el incidente al virrey y le sugirió que autorizara expresamente a la caja de Saltillo "por el beneficio que resulta a los prestamistas y al estado" El virrey Lizana turnó el asunto a la tesorería general con la orden de que se le expidiera la escritura al obispo; agregó que la orden del bando emitido el 5 de agosto anterior autorizaba expresamente a los ministros de las cajas a expedir escrituras e hipotecar las rentas necesarias para el pago de réditos, lo que era tanto como desautorizar la acción del intendente en contra del ministro de Saltillo. ${ }^{7}$

El préstamo patriótico urgente de fines del verano de 1809 generó una sustancial cantidad de recursos que debían enviarse a la península; de hecho, había dos barcos en Veracruz que esperaban salir inmediatamente del puerto. Pocas semanas después, en diciembre de ese año, se solicitó un préstamo puente "entretanto se reúnen en las cajas matrices los caudales que deben venir de ellas". Para la obtención de estos recursos se formaron juntas de vecinos pudientes de la capital virreinal. En cuestiones prácticas, los "beneméritos patriotas [...] han empezado a hacer efectivas sus ofertas, pasando a [...] las cajas reales". 8

La tendencia iniciada por Lizana de utilizar a los consulados para la colecta de los préstamos que tanto necesitaba la Península fue retomada por las autoridades peninsulares en enero de 1810 para hacer una nueva solicitud a los habitantes de la Nueva España, esta vez de mayores proporciones que las anteriores. El 10 de ese mes la hacienda española solicitó un préstamo por la cantidad de 20 millones de pesos por la intercesión de los tres consulados de la Nueva España. Para tal efecto, se creó una junta con la autoridad de decidir cuál renta se hipotecaría para la redención de los intereses y capitales; para hacer frente a estos pagos la junta también podía determinar gravámenes temporales sobre los productos de importación y exportación.

No era nueva la idea de utilizar a los consulados para la colectación de préstamos e impuestos. Antes de 1776 el consulado de México era el encargado del cobro de las alcabalas de la ciudad de México y su entorno. Esta forma de concesión le permitía al consulado contar con ingentes cantidades de numerario para prestar a la corona, lo que no excluía la posibilidad de actuar como intermediario financiero entre ésta y otros prestamistas. En atención al absolutismo propio de la época, para la segunda mitad de aquel siglo, la colecta del derecho de alcabala pasó en su totalidad a manos de la real hacienda de Nueva España. ${ }^{9}$ Sin

\footnotetext{
6 Ibidem, pp. 286-288.

7 Jáuregui, Luis, La real hacienda, 1999, pp. 239-240.

8 Gaceta de México, Ciudad de México, 2 y 6 de diciembre de 1809.

9 SÁnChez SANTIRó, Ernest, La hacienda reformada, 2001, pp. 143-145.
} 
embargo, había una figura fiscal —el derecho de avería — ${ }^{10}$ que cobraba el consulado de México y, después de 1795, los recién creados consulados de Veracruz y Guadalajara.

A diferencia de lo que ocurría en el pasado, los consulados solamente percibían el producto necesario para el servicio de las deudas generadas en favor de la Junta Central y, posteriormente, la defensa en contra de los levantamientos insurgentes. ${ }^{11}$ Sin embargo, fue sustancial el impacto administrativo de esta y otras decisiones en cuanto al pago de los intereses por parte de los consulados. En el reglamento que se expidió para la colectación de préstamo de veinte millones se determinaba que los productos destinados al pago de este, los trasladarían los administradores de aduanas a las cajas de los consulados. ${ }^{12}$ Aunque los consulados recibieron el dinero, en la realidad eran las cajas reales las que tenían el recurso ¿cómo harían el pago las corporaciones mercantiles? Ciertamente que, en dinero contante, ${ }^{13}$ pero no se debe descartar que también lo hicieran librando en contra de estas cajas (incluso cajas menores como las aduanas y la renta del tabaco) y en favor de los acreedores de la real hacienda. Esto significaba que los alcabaleros debían separar los recursos que propiamente pertenecían al Erario de los que estaban destinados a los consulados. Como se verá a continuación, el referido impacto administrativo implicaba que los funcionarios debían armar una contabilidad aparte y así reportarla a la caja real correspondiente.

Llama la atención que incluso en los tiempos más álgidos de la guerra, se mantuvo el sistema de aduanas y permanecieron los estanquillos, las cajas reales y quizá otras tesorerías menores. Asimismo, en la Ciudad de México continuó funcionando el aparato financiero que denominamos "hacienda pública". Gracias a la existencia de este sistema se pudieron colectar los recursos para la península primero y en contra de la insurgencia, después. A manera de ejemplo, presentamos el caso de alcabalatorio de Chautla, en el sur de la provincia de México, situado en el camino que iba de Acapulco a Puebla. Éste contaba con un administrador que se debió enfrentar a múltiples dificultades y contratiempos para cumplir su obligación. Tales contratiempos tuvieron que ver con las complejidades de la contabilidad y su certificación, por recuperar los mandatos fiscales originados en tiempos previos a la guerra y por cumplir sus obligaciones basándose en infor-

10 El derecho de avería consistía en el cobro del $0.5 \%$ sobre el valor de todos los géneros, frutos y efectos que se introducían y extraían por mar en todos los puertos. La avería la cobraban los recaudadores de alcabala que recibían un porcentaje de lo recaudado. La función de este derecho, que a partir de 1795 cobraban los consulados de México, Guadalajara y Veracruz, era la de fiscalizar la circulación de importaciones. El derecho de avería era un monto importante de ingresos para los consulados. IBARRA Romero, Antonio, "Mercado urbano y mercado regional", 2000, cap. 2.

11 Valle Pavón, Guillermina del, "El consulado de comerciantes", 1997, nota 147, pp. 405-406.

12 JÁuregui, Luis, La real hacienda, 1999, cap. 6, notas 74, 77 y 78, pp. 246-248. Según Sánchez Santiró, esta deuda fue garantizada con nuevos impuestos a la entrada de mercancías por los puertos de Veracruz y Acapulco, la elevación en dos puntos porcentuales de la tasa de alcabala (de $6 \%$ a $8 \%$ ) y el aumento del precio del tabaco en rama y manufacturado que expendía el monopolio real. SÁNCHEZ SANTIRó, Ernest, La imperiosa necesidad, 2016, p. 371.

13 Esto lo sugiere en parte el hecho de que los consulados podían emitir escrituras por el total de la cantidad prestada o por una fracción. Estas acciones serían negociables por la vía del endoso. Ibidem, p. 372. 
mación inexistente por la pérdida o destrucción de los archivos. Cuando llegó la rebelión, el administrador debió hacer frente al retraso en los correos por la inseguridad de los caminos, a la apropiación, siquiera ocasional, de los militares de los recursos de la alcabala y a los contribuyentes que cada vez eran más renuentes al pago o la actualización de sus ingresos. Y a pesar de todo esto, hasta el final se mantuvo la oficina de aquella alcabala y atendiendo a las órdenes de la dirección general de alcabalas, que se mantuvo con el mismo director aun después de consumada la independencia. ${ }^{14}$

La problemática resumida en este ejemplo — que refiere a una zona que en algunos periodos fue azotada por la guerra - permite pensar que, reducidas, continuaron cobrándose las alcabalas a lo largo del virreinato. Y como no iba a ser así si sabemos que fue por este conjunto de oficinas que las autoridades virreinales aplicaron una buena parte de la fiscalidad extraordinaria. ${ }^{15}$ Por otro lado, si esto sucedía en las aduanas internas, podemos suponer que igualmente ocurría con los estanquillos del tabaco, con el pago de los quintos reales de la minería e impuestos menores.

Ya se mencionó el problema que los contribuyentes dejaron de pagar y es probable que así fuera. Sin embargo, también se debe apuntar que, con motivo de la guerra, muchos hombres se unieron a la tropa realista o insurgente, lo que indica una posible escasez de funcionarios locales. Siguiendo el ejemplo del alcabalatorio de Chautla, lo anterior se tradujo en la necesidad de establecer el sistema de igualas y encabezamientos para reducir los trámites administrativos del alcabalero. Tal sistema se prestaba a la negociación de pagos y al ocultamiento de ventas. ${ }^{16}$

Los problemas a los que se enfrentaban los recaudadores de impuestos tenían que ver también con la propia guerra en contra de la insurgencia. Por una parte, se debe considerar el hecho que, común en toda contienda bélica y por ambos bandos, el saqueo y la rapiña fueron una manera de compensar a los hombres del ejército que por lo general tenían poca paga o ésta llegaba mucho tiempo después de la acción. Por otro lado, desde el punto de vista formal, vale la pena comentar la forma como en lo general se hacían los pagos a oficiales, sargentos, tropa y, tal parece, también se distribuían caballos, armamentos y demás utensilios.

Estas acciones, netamente administrativas, se hacían por vía de los comisarios que una vez al mes debía realizar una revista de oficiales, sargentos, cabos, etc. En este documento, que debía presentarse al detalle y resumido, se confirmaba la presencia de cada uno de los hombres o su localización al momento de la revista. Igualmente se consignaba la suma en dinero que le correspondía, así como las compensaciones de campaña, premios de valor, etc. Al final de la relación

14 JÁUREGUI, Luis, "Una visión particular", 2021, en prensa.

15 Al respecto véase SÁnchez SANTIRó, Ernest, La imperiosa necesidad, 2016, cap. 4.

16 Una iguala es un pacto con el Erario en el que el contribuyente se compromete al pago de sus impuestos por vía de una cantidad fija. La base del impuesto era la venta de algún producto o productos. Por ejemplo, en el caso de las igualas de Cuautla de Amilpas del año 1789, un conjunto de changarros y tendajos pagaba de iguala 345 pesos anuales, lo que significaba (cuando el pago era de $8 \%$ sobre las ventas) una actividad de ventas de 4,312 pesos. SÁnchez SANTIRó, Ernest, "Igualas, producción y mercado", 2001, p. 13. 
detallada, debía darse cuenta de los hombres que en el periodo ingresaron al cuerpo y los que no estuvieron presentes en la revisión (altas y bajas). La lista de revista, firmada por el comisario y el capitán o un oficial superior, debía presentarse a la tesorería más cercana. ${ }^{17} \mathrm{Al}$ parecer, después de este procedimiento, que generaba un acuse de recibo por parte del tesorero, en la caja se hacían los asientos correspondientes y en algún tiempo futuro (suponemos que breve pues se trataba de sueldos mensuales) se hacía entrega del dinero al comisario y éste lo repartía, según la revista, al cuerpo comisariado. Es seguro que este procedimiento tuvo infinidad de detalles y variantes; valga aquí señalar, como excepción, el caso de un jefe militar, Joaquín de Arredondo, comandante de las Provincias Internas de Oriente entre 1814 y 1821 quien al parecer echaba mano de los dineros en la tesorería (la que fuera) y los utilizaba para el pago de sus hombres. En noviembre de 1818, Arredondo respondía al virrey Apodaca un exhorto para que remitiera una relación de los pagos hechos a la tropa en aquellas provincias. Dado el comportamiento previo del coronel catalán, es muy probable que no enviara ninguna lista, más aún porque no le tenía mucha admiración al conde de Venadito a quien veía como un burócrata sin autoridad. ${ }^{18}$

Al igual que Arredondo, desde los primeros años de la insurgencia varios militares colectaban recursos generados y guardados en las aduanas alcabalatorias. De algunos casos al respecto da cuenta el trabajo de Espinosa Aguirre quien apunta que, ante la escasez de fondos a partir de finales de 1813, los intendentes debieron buscar otros medios para hacerse de recursos: plata, pólvora, tabaco "e incluso las aduanas". Los jefes militares también echaron mano de los recursos del rey. Un caso conocido es el del comandante Melchor Álvarez que se hallaba con su batallón expedicionario de paso por Xalapa, se halló con el convoy que llevaba la plata que en forma de lingotes y moneda debía llegar a su destino que era el puerto de Veracruz. Ante las urgencias (y la posibilidad de que, en el mejor de los casos lo abandonaran sus hombres), en el camino Álvarez dispuso del cargamento de metal para el pago de sus tropas. Años después, cuando la situación era aún más apremiante en materia de recursos, el intendente de Guanajuato comunicó al virrey que se habían extraído cantidades de las tesorerías de tabaco y aduanas para habilitar las urgentes necesidades del general Pascual Liñán. ${ }^{19}$

Tomar recursos de la tesorería o caja en donde los hubiera respondía a la necesidad apremiante de pagarle a la tropa; de otra forma ésta se iba por su rumbo o, más peligro aún, se unía a las filas insurgentes. Cierto es que este problema es propio de la guerra, pero se debe reconocer que el virreinato de la Nueva España ingresó a lo que después denominaríamos las guerras de independencia con un aparato administrativo deficiente, con recursos menguados, sin capacidad de recuperación en el corto plazo y en un ámbito económico desfavorable. Desde 1808 se vio afectada la añeja capacidad de negociación de la corona española con

\footnotetext{
17 Un ejemplo de esto en AGN, Indiferente de Guerra, caja 21, Exp. 24 al 34.

18 Sobre la tensa relación entre Arredondo y Apodaca en los años posteriores a la invasión de Mina, véase Folsom, Bradley, Arredondo, 2017, cap. 12.

19 Espinosa Aguirre, Joaquín Edgardo, "Los abusos de la oficialidad", 2015, pp. 171-175.
} 
los distintos grupos sociales del virreinato. El derrocamiento del virrey Iturrigaray pocos meses después y la insurrección iniciada en septiembre de 1810, tuvieron enorme impacto sobre las estructuras administrativas. Luego, en este ambiente y en plena contienda, se vinieron a agregar reformas imperiales (esta vez liberales) en la manera como los territorios debían administrarse, reformas que en el espacio virreinal se aplicaron con variantes importantes respecto a la ley y que luego, a finales de 1814, se abrogaron. Vemos así, como resultado lógico, la modificación de muchas rutinas y la fragmentación del conocimiento acumulado. Ciertamente, esto ocurre aun y cuando no hay guerra; los funcionarios se mueren o se retiran y en cierto sentido se pierde experiencia y conocimiento. Lo que ocurre en la Nueva España durante los últimos años de su existencia es la desarticulación de una lógica de funcionamiento adquirida y construida durante años. ${ }^{20}$

La dislocación de las rutinas administrativas se dio, en primer término, por la guerra en sí. Es conocido el caso de Manuel Royuela que, ante la derrota realista en las goteras de Saltillo, en Aguanueva, emprendió la marcha de Monclova a Río Grande donde, por cierto, fue asaltado y despojado de los tesoros de la real hacienda. ${ }^{21}$ Igualmente relevante fue el caso de Cayetano de Landazuri, administrador de diezmos de Monterrey que, por falta de personal, recibió instrucciones giradas por Calleja en enero de 1816 para que desplazara caudales y oficina a la ciudad de Saltillo. ${ }^{22}$ Todo el proceso que desató esta decisión sugiere por una parte que aun cuando la rebelión insurgente se había reducido, continuaba la falta de personal para administrar las oficinas de la hacienda virreinal. Segundo, muestra también que, a pesar de esto último, algunos procedimientos continuaban como en tiempos de paz. Landázuri apuntó que no tenía inconveniente en trasladar la recaudación a Saltillo pero que no tenía fondos para emprender el cambio. La consulta provocó un expediente que muestra la operación de la intendencia de San Luis Potosí: el intendente Acevedo consultó al promotor y al asesor fiscal, que dieron su recomendación; Acevedo subió la consulta a la Junta Superior de Real Hacienda que a su vez consultó al fiscal Sagarzurrieta que emitió largo dictamen; a final de cuentas el virrey Apodaca decidió según la decisión del fiscal. ${ }^{23}$ Lo anterior sugiere que si bien los tiempos de guerra distorsionaron la administración de los recursos del erario novohispano, la relativa paz que se experimentó a partir de 1816 permitió la recuperación de algunas de las tareas más importantes del aparato fiscal novohispano.

Se puede palpar que, por falta de personal, se unieron algunas tesorerías. Es seguro que esto tampoco fuera nuevo; sin embargo, parece que esta práctica se agravara con el decreto de consolidación de vales reales de diciembre de 1804 . Esta disposición ideó la creación de juntas de consolidación —una en la Ciudad

20 Galván Hernández, José Luis, “La voz de la jurisdicción”, 2020, p. 79.

21 Vizcaya Canales, Isidro, En los albores, 1976, pp. 105, 127 ss.

22 La oficina de diezmos se había creado en 1804 con motivo de la creación del "nuevo noveno decimal", un impuesto creado con la consolidación de vales reales y que en Monterrey se había adjuntado a la caja de la administración de tabacos. Al respecto JÁUREGUI, Luis, La real hacienda, 1999, pp. 226-227.

23 José Cayetano de Landazuri al intendente de San Luis Potosí, Monterrey, 11 de enero de 1817, AGN, Diezmos, caja, 0575, Exp. 001. 
de México y otras subalternas en las diócesis del virreinato- que se harían cargo de "averiguar prolija y prontamente [...] todas las obras pías, capellanías [...así como] bienes raíces, censos y capitales que de cualquier modo les pertenezcan". También se creó una tesorería - la caja de consolidación - cuyo trabajo era el de llevar registro de los acreedores del rey y el cálculo de los réditos y capital que a cada uno se le debía pagar. ${ }^{24}$ Así, el trabajo adicional al que por la consolidación debían encarar los funcionarios del rey se repartía entre la caja de consolidación y las cajas reales, que a fin de cuentas eran las que cobrarían y resguardarían los caudales generados por los nuevos impuestos. Se percibe así una "repartición" de tareas de frente a las urgencias de la corona, repartición que trataba de evitar el descontento de una burocracia que, en atención a las palabras de Revillagigedo, no estaba muy dispuesta a ver incrementadas sus tareas. ${ }^{25}$

De todas formas, parece que la unión de las tesorerías reales y las cajas de consolidación aumentó el trabajo del funcionariado virreinal. ${ }^{26}$ En octubre de 1809 los ministros de la Tesorería General en la Ciudad de México externaron su queja por el hecho de que los acreedores cobraban réditos en cajas provinciales e incluso en las administraciones de tabaco. Al parecer, el asunto se desordenó por la autorización de hacer negociables los papeles de esta deuda y fue por lo que los ministros recomendaron que fueran los juzgados de capellanías los únicos autorizados para cobrar los réditos y que estos cuerpos se hicieran cargo de pagar a los demás acreedores. Quizá la queja tuviera que ver solamente con este hecho; sin embargo, no se debe descartar que, para el pago de los réditos, se habían creado impuestos adicionales que si bien es probable que contabilizara e incluso cobrara la iglesia (por el tipo de gravamen) ${ }^{27}$ eran los funcionarios del Erario novohispano los que debían llevar registro de los pagos que en calidad de réditos hacía la real hacienda de Nueva España a sus acreedores. Según Gisela von Wobeser:

[...] los ministros de la real hacienda [...] atendieron las cajas de consolidación, instaladas en las tesorerías reales. Les correspondió cobrar las cantidades ingresadas por concepto de consolidación, pagar los réditos a los propietarios de los capitales de Consolidación, llevar un registro minucioso de todos los caudales que ingresaban a las tesorerías y rendir cuentas sobre los mismos. Como no se designaron funcionarios adicionales para esta tarea, a los ministros de la real hacienda se les acumuló el trabajo, y lo mismo pasó con el resto del personal de las tesorerías, como cajeros, cargadores y contadores de moneda. Muchos de estos empleados tuvieron que trabajar en forma gratuita para la consolidación pues no recibieron compensaciones salariales. ${ }^{28}$

$\overline{24}$ Real despacho general de 26 de diciembre de 1804 sobre la venta de los bienes de obras pías en los reinos de Indias, Madrid, 26 de diciembre, 1804, en AGN, Consolidación, vol. 1, f. 11.

25

26

27

28 Pietschmann, Horst, Las reformas borbónicas, 1996, pp. 294-296.

Von Wobeser, Gisela, Dominación colonial, 2003, pp. 64-65.

Entre otras, estas cargas adicionales fueron: nuevo noveno, anualidades, indulto apostólico, subsidio eclesiástico, bienes libres de temporalidades, contribución temporal y aumento de la limosna de bulas de Santa Cruzada. Al parecer también se aplicó una contribución sobre legados y herencias en las sucesiones transversales. Ibidem, p. 46.

Ibidem, pp. 64-65. 
Ahora bien, si con la unión de tesorerías la intención era que no se incrementaran los trabajos de los funcionarios de la hacienda novohispana, ella se quedó en eso: intención. La problemática detrás de esto tenía que ver tanto con la circunstancia - insurgencia en el interior, pero también inestabilidad generalizada a nivel global - como con las particularidades de la contabilidad de la época y lo que se consideraba rendición de cuentas. ${ }^{29}$ Así, el incremento en las labores de los funcionarios de la real hacienda novohispana respondía, por una parte, a que cada impuesto tenía un objeto específico de gasto. Así, el nuevo noveno decimal, por ejemplo, estaba destinado al pago de réditos de los dineros generados por la Ley de Consolidación de Vales Reales de diciembre de 1804. De forma similar, con motivo del préstamo patriótico de 20 millones de pesos solicitado en septiembre de 1810 para el apoyo a la guerra contra las huestes de Bonaparte, el Erario de Nueva España debió pedir dinero prestado a los consulados de México, Veracruz y Guadalajara. Para hacer frente a esta deuda, la hacienda real incrementó la tasa del derecho de alcabala de $6 \%$ a $8 \%$.

La peculiaridad de la contabilidad de la época exigía que en cada aduana (aquí nos referimos a las aduanas internas o alcabalas) se llevara contabilidad aparte de esos dos puntos porcentuales y que los registros se entregaran tanto a la dirección general de aduanas como a los consulados en donde se hallara la aduana alcabalatoria. Estos registros contables eran remitidos por la dirección general de alcabalas a la tesorería general o matriz de la Ciudad de México, lo que le permitía a ésta gastar, por vía de libramientos en contra de las cajas provinciales que a su vez libraban contra las aduanas, en el lugar en donde se hallara el numerario físico. Los consulados operaban de la misma manera, lo que obligaba al alcabalero, recaudador, estanquillero, etc. a realizar todos los movimientos contables para el erario y para los consulados. ${ }^{30}$

En octubre de 1811 el administrador de rentas de Chautla enviaba a la dirección general de alcabalas en la Ciudad de México tres certificados de entero de recursos en la real caja de Puebla. Este dinero daba cuenta de lo colectado en esta aduana del sur de aquella intendencia correspondiente al derecho de alcabala, al de aguardiente de caña y al impuesto para el real desagüe. A la vez enviaba a la dirección general los tres estados contables, para lo cual pedía al titular que le hiciera llegar los acuses de recibos y así "acreditar [...] el corto mérito que he contraído con este servicio al soberano". ${ }^{31}$ Días después, el director general manifestaba su extrañeza por no ver registrado de manera específica el aumento de

29 "La exagerada atención a la seguridad y el control había impulsado a la Corona a emitir reglamentaciones burocráticas en trámites que en la práctica demostraron ser engorrosas, pero que requerían mucho tiempo y esfuerzo de los funcionarios”. Pietschmann, Horst, Las reformas borbónicas, 1996, p. 295.

30 Sánchez Santiró apunta que fue el préstamo de 20 millones el primero que obligó a la "separación" de ramos para distinguir el dinero del Erario del que correspondía al Consulado de México. SÁNCHEz SANTIRó, Ernest, La imperiosa necesidad, 2016, pp. 360, 373.

31 Ignacio María de Ibarrola, administrador de rentas de Chautla, al director general de la real renta de alcabalas, Chautla, 7 de octubre de 1811, en AHH, vol. 461, Exp. 17. 
alcabala. ${ }^{32} \mathrm{El}$ asunto al parecer no tuvo solución pues en esos días los insurgentes invadían aquella región, lo que obligaba al alcabalero a ponerse a salvo "con archivo e intereses de la renta a mi cargo". ${ }^{33}$

Lo anterior sugiere que los administradores de alcabala debían llevar contabilidades aparte para cada impuesto, derecho y sobretasa. En el caso del préstamo de veinte millones, se debían además hacer contabilidades aparte y remitirlas tanto a la dirección general como al consulado. A esto se debe agregar un aspecto muy importante que era el hecho de que cada acción debía contar con un comprobante. Cierto es que aún hoy día esto es el uso generalizado en cuestiones de dinero; sin embargo, en aquellos años, la situación era bastante más compleja pues el funcionario que recibía un recurso, por ejemplo, de alcabala, se hacía cargo de éste y sólo hasta que tuviera un descargo oficial continuaba siendo deudor de su empleador. ${ }^{34}$ Así, por ejemplo, si el administrador de la alcabala recibía cierta cantidad de pesos por este concepto, debía extender un certificado de cargo, firmado y con el visto bueno de la autoridad del partido, que era el subdelegado; con eso comprobaba que había recibido dinero de los contribuyentes. Días o meses después, la caja real, al recibir el dinero de parte del administrador, debía extender un (otro) certificado de cargo que comprobaba que el alcabalero había ingresado los dineros en esa tesorería. Seguidamente, el administrador debía remitir este certificado a la dirección general que a su vez le hacía llegar el recibo correspondiente. En mayo de 1811, el administrador de alcabalas de Chautla afirmaba: "quedo inteligenciado estar hipotecado el $8 \%$ de alcabalas ${ }^{35}$ para el préstamo patriótico, entregando por separado en las cajas reales ambas cantidades [se refiere al $6 \%$ de la alcabala ordinaria y $2 \%$ del incremento para el pago del préstamo patriótico de veinte millones] y remitido al consulado el duplicado de las certificaciones, quedando otra en mi poder para documentar las cuentas al tiempo de su remisión". ${ }^{36}$ Pocos días después, el director general de alcabalas respondía al administrador "le advierto que de las certificaciones que por duplicado le han de dar en cajas reales de los enteros que haga ha de remitir los duplicados al consulado y el principal a esta dirección general para que conste a la misma de los enteros". 37

El gasto se debía comprobar con la orden correspondiente, idealmente emitida por el superintendente de hacienda y la Junta Superior de Real Hacienda, que se reunía una vez a la semana para estos asuntos. Sin embargo, cuando se trataba de una cuestión de emergencia, las decisiones de gasto se hacían en las Juntas

32 Agustín Pérez Quijano, director general de alcabalas a Ignacio María de Ibarrola, México, 16 de octubre de 1811, en AHH, vol. 461, Exp. 17.

33 José Antonio de Solís al director general de alcabalas, Chautla, 23 de octubre de 1811, en AHH, vol. 461, Exp. 17.

34 SÁnchez SAntiró, Ernest, "Genealogía, contenido y consecuencias”, 2014, pp. 20-21.

35 Aquí el administrador comete un error. Se hipotecó el $2 \%$ de la alcabala incrementada de $6 \%$ a $8 \%$.

36 Ignacio María de Ibarrola a Agustín Pérez Quijano, Chautla, 15 de mayo de 1811, AGN, AHH, vol. 461, Exp. 17.

37 Agustín Pérez Quijano a Ignacio María de Ibarrola, México, 21 de mayo de 1811, AGN, AHH, vol. 461, Exp. 17. 
Provinciales de Hacienda que aun así debían tener la autorización de la junta superior. ${ }^{38}$ Por supuesto, el gasto debía venir justificado por un recibo o factura, en donde se consignara la cantidad erogada. En el libro de datas (descargos) debía anotarse el concepto, la cantidad y fecha de la data correspondiente; cada soldado debía extender un recibo por el sueldo recibido; igualmente cada proveedor y, como ya se mencionó, cuando se tratara de un monto grande, por ejemplo para el pago de algún regimiento que estuviera acuartelado en otro lugar, un habilitado o comisario de la tropa extendía el recibo correspondiente que incluía la nómina y el pago de cada uno de los soldados, igualmente debía hacerlo con las provisiones y utensilios que llevara para el sostenimiento del regimiento, presidio o situado. ${ }^{39}$ Si se entregaba dinero destinado a la caja real —o a otra tesorería - se debía obtener el recibo de parte del arriero, que a su vez debía obtener un documento similar de parte de los ministros de la caja correspondiente, a su vuelta el arriero debía entregarlo al administrador. Si se honraba un libramiento extendido por alguna autoridad superior o por algún miembro autorizado del consulado, se debía generar un documento similar; si se expendía algún producto como tabaco, azogue o pólvora, el administrador debía realizar una factura del producto vendido. Todos estos acuses de recibo, llamados comprobantes de data, debían mantenerse y justificarse con alguna disposición superior, denominada: "razón que daba origen al ramo". 40

Las complicaciones del sistema de rendición de cuentas y contabilidad de la época responden fundamentalmente a la manera como se concebía el servicio financiero al gobierno de la monarquía española. Al respecto, Sánchez Santiró lo postula claramente:

[...] los libros de cargo y data eran instrumentos de control sobre el comportamiento de los oficiales reales en el manejo de los ramos del real erario, con el propósito de personalizar e individualizar las posibles responsabilidades en el manejo de fondos de la corona. De ahí que tuvieran una nomenclatura judicial según la cual el oficial real recibía unos fondos que pertenecían a la real hacienda o a un particular [...]: se hacían cargo de ellos. Por lo tanto, eran recursos sobre los cuales adquirían una responsabilidad frente a una autoridad judicial superior: el tribunal de cuentas de la Ciudad de México. De igual forma, cuando entregaban esos recursos a otra autoridad o a un particular y quedaba registrado en una partida de la data, en ese momento se estaban "descargando" de la responsabilidad que habían adquirido al recibirlos". ${ }^{41}$

La exigencia de los requerimientos de comprobantes, recibos, facturas, certificados, etc., no es muy diferente a la de hoy en día. La diferencia radica en lo

38 Pietschmann, Horst, Las reformas borbónicas, 1996 [1972], pp. 171 y 177.

39 SÁnchez SANTIRó, Ernest, "El aprovisionamiento de las fuerzas", 2018, pp. 361-368.

40 "Razón que daba origen al ramo (real cédula u orden, mandamiento virreinal, ordenanza, etc.)", SÁNCHEZ SANTIRó, Ernest, Ordenar las cuentas, 2019, p. 143.

41 SÁnchez SAnTiRó, Ernest, "Genealogía, contenido y consecuencias", 2014, pp. 20-22. Subrayado en el original. Conviene agregar que, cuando la autoridad requería saber las cantidades que había en alguna tesorería, solicitaba un corte de caja, tanteo o realizaba una visita. SÁNCHEZ SANTIRó, Ernest, "La reforma de los mecanismos", 2019, p. 214, nota 23. 
que sugiere la cita anterior: el funcionario del pasado era responsable de todos los recursos que recibía como empleado del rey. Una vez recibidos, debía comprobar que había hecho buen uso de estos; en caso contrario, se le iniciaba un proceso judicial que bien podía durar hasta después de su muerte.

Sin temor de exagerar, la realidad de la administración financiera de la Nueva España era muy compleja; así lo fue durante todo el tiempo de la dominación española y es seguro que lo fuera aún más durante los años de la lucha insurgente. De hecho, no sería muy arriesgado afirmar que para inicios de la rebelión y mientras ésta duró, una buena parte del edificio intendencial - diseñado, entre otras cosas, para dar unicidad a la administración fiscal - ya no funcionara siquiera con los defectos que tenía a fines del siglo anterior y que surgían de las carencias originales del ordenamiento de 1786. Como hemos visto, cuando disminuyó la rebelión las intendencias comenzaron a funcionar relativamente mejor, pero en los tiempos en que más se destacaba la labor burocrática de Apodaca que, por la vía administrativa, hizo todo lo posible por restaurar un ethos que ya no existía: ese conjunto de creencias e ideales que habían caracterizado la ideología del imperio. ${ }^{42}$

\section{LA PROBLEMÁTICA DE LAS DIPUTACIONES PROVINCIALES}

En términos de rutinas y procedimientos administrativos, el ya de por sí distorsionado aparato financiero del virreinato recibió un impacto adicional con el establecimiento de las diputaciones provinciales. Éstas tuvieron un primer periodo de vigencia en los años que se aplicó por las cortes reunidas en Cádiz un modelo liberal de gestión fiscal. Hemos explicado en otra parte las generalidades de este nuevo esquema. ${ }^{43}$ Las cuestiones relacionadas con la aplicación en Nueva España de la fiscalidad liberal en materia de tributos han sido ampliamente estudiadas por Serrano Ortega y Sánchez Santiró. ${ }^{44}$

Para situar en contexto, regresemos a la figura de los intendentes. El ejercicio no está de más pues, a fin de cuentas y en algunos casos, estos personajes fueron también jefes políticos de las diputaciones provinciales, lo que sugiere, una vez más, la falta de cuadros para la administración provincial.

Los intendentes eran encargados de dirigir el desarrollo económico de la provincia. En un gobierno con visos de tecnócrata, ${ }^{45}$ esto abarcaba las cuatro causas. Sin embargo, cuando se establecieron los intendentes en Nueva España, la causa de guerra era atendida de manera tangencial, toda vez que excepto en el norte (en donde había comandantes militares) había pocas razones para atender la causa de guerra fuera de alguna rebelión o motín. Si bien en 1764 Juan de Villaba había intentado establecer un sistema de milicias es claro que, para los

42 AnNA, Timothy E., "The Last Viceroys", 1976, pp. 62-65.

43 JÁuREGUi, Luis, "Nueva España y la propuesta", 2001, pp. 83-116.

44 Serrano Ortega, José Antonio, "Cadiz Liberalism", 2005, pp. 255-284; Serrano Ortega, José Antonio, Igualdad, uniformidad, 2007. SÁNCHEZ SANTIRó, Ernest, "Guerra y restauración”, 2001; SÁnChez SANTIRó, Ernest, La imperiosa necesidad, 2016.

45

Al respecto véase Pietschmann, Horst, "Las múltiples dimensiones”, 2018, pp. 65-90. 
hombres de las clases altas, el otorgamiento de privilegios y manifestaciones formales de prestigio (uniformes, galones, hebillas, etc.) así como el fuero militar significaban un enorme aliciente para alistarse ${ }^{46}$ Esto no ocurría tanto o casi nada con las clases bajas, con otra percepción de las cosas. En todo caso, para la segunda década del siglo XIX muchos funcionarios locales tenían algún atributo castrense, aunque en la realidad fueran más burócratas que militares.

Como resultado de o anterior, poco después del inicio de la insurgencia es que veremos una militarización de las labores administrativo-fiscales de localidades y provincias. En esta situación se hallaban tanto los "fieles realistas" creados por el plan Calleja de 1811, como los intendentes que, como ha mostrado Moreno Gutiérrez, eran militares de origen pero que, fundamentalmente hacían labores burocráticas. Con la rebelión, a algunos se les adjuntó un comandante y al paso de los años, intendentes y comandantes se unieron en un solo personaje, en lo que Moreno denomina "mando unificado"; tal situación se repitió en el caso de algunas subdelegaciones. ${ }^{47}$ Aquí se debe señalar que no se trata de la totalidad del territorio novohispano pues las comandancias de las provincias internas fueron zonas militarizadas en las que el comandante -Arredondo, en el caso de las de Provincias de Oriente y Diego García conde en las de Occidente-tenía poder político y militar. Esta situación se intentó corregir en junio 1818 cuando Fernando VII ordenó a Apodaca y Arredondo a trabajar en la implementación de una forma de diputación provincial con sede en Saltillo; ésta no se estableció por la muerte de los dos candidatos. Poco tiempo después, el monarca redujo las atribuciones de los comandantes, de forma que reportaran al virrey y se atuvieran únicamente a las cuestiones militares; en el caso de Arredondo, éste "obedeció, pero no cumplió" al tiempo que se intensificaba la invasión de contrabandistas y posesionarios norteamericanos en la zona oriente de la provincia de Texas. ${ }^{48}$ Mismo asunto en Yucatán, en donde desde 1818 las facultades política y militar quedaron unidas en el intendente Miguel de Castro y Araoz. Solamente queda mencionar el caso más emblemático: el de José de la Cruz en la provincia de Nueva Galicia quien, a pesar de la presencia de un intendente, reunió en su persona el control político y militar. ${ }^{49}$

Por lo tanto, en el tiempo en que se restableció el régimen constitucional en marzo de 1820, en la mayoría de las provincias los mandos político y militar se hallaban unidos. Esta situación fue de utilidad en los tiempos de guerra contrainsurgente y no fue del todo irracional. Un intendente encargado únicamente de cuestiones políticas sin duda ocupaba mucho tiempo en negociar los recursos para atender las urgencias del ejército; no así un intendente con plena conciencia de la necesidad de atender con relativa premura los requerimientos castrenses. Ahora bien, los intendentes en las capitales provinciales no podían estar plenamente al

\footnotetext{
46 Archer, Christon I., The Army in Bourbon, 1983, pp. 299.301. Puede ser incluso que, una vez confirmado por el rey, el rango militar se conservaba, con todas las preeminencias hasta el día de la muerte.

48 Folsom, Bradley, Arredondo, 2017, cap. 13.

49 Moreno GutiÉrrez, Rodrigo, "Intendentes e independencia”, 2019, pp. 360-361.
} 
tanto de las necesidades de la tropa; de ahí que los militares adoptaran decisiones sobre recursos y luego las comunicaran a los intendentes. Por ejemplo, en junio de 1813, Iturbide solicitó a los pueblos de Guanajuato que informaran de los recursos disponibles para asistir a las tropas urbanas; de esta acción - y no falto de cierta ironía - Iturbide mantuvo al tanto al intendente, comandante, cura y subdelegado del partido para que "se facilite y simplifique la dación y revisión de dichas cuentas". ${ }^{50}$ La idea que desvela la ironía del vallisoletano era: "soy capaz de avisarle a quien sea con tal de que no ponga obstáculos para atender las necesidades del ejército". Una situación más urgente fue la ya referida en el caso de Melchor Álvarez. Pocos días después del caso de Guanajuato, llegaba a Xalapa un convoy transportando plata del rey. Álvarez solicitó "oficialmente" al comandante y escolta del convoy que le proporcionara recursos para dar de comer y vestir a las tropas. Para evitar tan descarada confiscación, el ayuntamiento de Xalapa ofreció establecer un arbitrio a las platas del convoy; esto es, un cuerpo instituido aplicaba un impuesto al numerario del rey por su tránsito por aquella villa. ${ }^{51} \mathrm{Si}$ bien la solución del asunto era políticamente hábil, ésta recibió la respuesta lógica por parte de Álvarez que fue la confiscación de la plata. La explicación que dio al virrey fue que temía que sus propios hombres emplearan las bayonetas en contra de la gente para conseguir esos recursos. ${ }^{52}$ Es seguro que fueron muchos los casos como los dos expuestos; la idea que se quiere conferir es que los comandantes militares prefirieron pedir perdón al virrey antes que pedir permiso a las autoridades instituidas.

Queda razonablemente claro que los militares realistas se despachaban de los recursos del rey. Para tiempos de la trigarancia, ya con las diputaciones provinciales instituidas, Rodrigo Moreno muestra que las facultades fiscales continuaron delegadas en cada provincia en un "administrador general de rentas unidas nombrado por el comandante general [...] y aprobado por el primer jefe [que era Iturbide]". 53

Sin ocuparnos ahora de las contribuciones directas/indirectas, préstamos, donativos y confiscaciones, ¿quién cobraba en las provincias? ¿acaso el "administrador de rentas unidas" tenía un ejército de cobradores a su disposición? No. Moreno apunta que una parte de la recaudación en aquellos meses se le delegó a los ayuntamientos: ${ }^{54}$ en concreto, a un regidor comisionado que entregaba a un regidor/tesorero que informaba al jefe político de la provincia. En el caso de que no hubiera ayuntamiento, este autor apunta que se haría uso del subdelegado y, en zonas rurales, los dueños de ranchos y haciendas descontarían de sus jornaleros la exacción o cuota correspondiente. ${ }^{55}$ Por otro lado, más importante aún para

50 Iturbide a Calleja, Silao, 25 de junio de 1813, en Archivo General de la Nación México, Documentos para la historia, vol. 1, p. 62.

51 Archer, "Soldados en la escena", 2005, pp. 149-150.

52 Espinosa AguirRe, Joaquín Edgardo, "Los abusos de la oficialidad", 2015, pp. 151-152.

53 Moreno GutiérRez, Rodrigo, La trigarancia: fuerzas armadas, 2016, pp. 334-377.

54 Un aspecto que también señala AlCAUTER GuZmán, José Luis, subdelegados y subdelegaciones, 2017, pp. 313-314.

55 Moreno Gutiérrez, Rodrigo, La trigarancia, 2016, p. 339. 
el ejército trigarante era la colectación de los recursos provenientes del derecho de alcabala. Aunque con el decreto del 3 de junio de 1821, Iturbide "des[hizo] gran parte de la obra fiscal del periodo 1810-1821", ${ }^{56}$ cierto es que en la última parte de la guerra de independencia presenciamos lo que Moreno denomina una guerra por el control de las alcabalas. ${ }^{57}$

Lo relevante aquí es que en los últimos siete meses de la dominación española la fiscalidad se aplicó haciendo uso de la estructura de las diputaciones provinciales, pero con una mayor presencia de la comandancia militar para distribuir los recursos entre el elemento castrense. Así, continuó utilizándose el aparato recaudatorio heredado de tiempos más prósperos de la dominación española: concretamente, los ayuntamientos/diputaciones provinciales, las subdelegaciones y las aduanas internas.

Con la presencia de las diputaciones provinciales, queda un elemento a considerar en todo este aparato administrativo fiscal de las postrimerías coloniales. ¿A dónde iban a parar todos los caudales recogidos por concepto de impuestos y demás cargas no tributarias? La respuesta se puede delinear con unos breves ejemplos tomados de la experiencia de dos cuerpos provinciales - Nueva Galicia (Guadalajara) y Yucatán - en los meses previos a la consumación de la independencia. ${ }^{58}$

Para el caso de Nueva Galicia, en esos días el jefe político y el comandante militar de la diputación eran la misma persona; en concreto, José de la Cruz. El intendente era otro individuo: Antonio de Ulloa. En días previos, ambos personajes enviaron sendos oficios a la diputación provincial en donde manifestaban la falta de fondos en la tesorería nacional de la provincia para pagar "las tropas necesarias en las actuales circunstancias". Esta situación, expresaba Ulloa, se había comunicado "al excelentísimo señor virrey como superintendente de la hacienda pública en toda la extensión de Nueva España”. El virrey le contestó con dos reales órdenes en donde se autorizaba a las diputaciones provinciales en España "a que auxilien a los intendentes para que puedan llenar las obligaciones y gastos públicos del Estado, y aun las autoriza para que puedan valerse de arbitrios a propósito para el efecto". El virrey exigió a la diputación provincial usara de tal facultad y meditara los medios más oportunos para el auxilio requerido. La diputación provincial, temerosa de que se extraviara la "opinión de los pueblos" en términos de la obediencia que se debe al legítimo gobierno, amén de la pobreza en la que se encuentra, tuvo de muy poca utilidad la autorización que otorgaban las reales órdenes. Prefirió pedir créditos en especie "a los fabricantes y comerciantes que tuvieran géneros a propósito"; la provisión de estos bienes se pagaría en abonos mensuales y saldría de la aduana de Guadalajara y de los diezmos que

56 SÁNCHEZ SANTIRÓ, Ernest, Las alcabalas mexicanas, 2012, cap. 3.

57 Moreno Gutiérrez, Rodrigo, La trigarancia, 2016, pp. 356-357.

58 Aunque estos ejemplos responden a la disponibilidad de información, también es importante considerar que Nueva Galicia y Yucatán fueron las primeras provincias en declararse desligadas de la Ciudad de México en 1823, dando paso a la discusión sobre la posibilidad de aplicar la forma federada en México. Al respecto, BARRAGán Barragán, José, Introducción al federalismo, 1978. 
adelantaría la catedral correspondiente al año de $1822 .{ }^{59}$ Esto indica que, ante la urgencia, se "echaba mano" directamente de las fuentes donde se recaudaba; es decir, dejaban fuera del asunto a las tesorerías provinciales y sus ministros. ¿Significaba esto que en mayo de 1821 no había tesorería en la provincia de Nueva Galicia? Sí la había; pero la problemática expresada en el párrafo anterior señala "falta de fondos en la tesorería nacional" y en otras actas de esos meses se hace mención de "ingresos con salidas de la tesorería nacional"; 60 se debe incluso señalar que en el puerto de San Blas trabajaba un ministro de hacienda pública. ${ }^{61}$

El asunto se presta, sin embargo, a confusión pues la constitución de Cádiz daba permiso a las diputaciones provinciales para que crearan arbitrios en el caso de que se requiriera alguna obra para el bien común. En Ultramar, señala el código gaditano, las diputaciones podían hacer uso de estos arbitrios sin autorización de las Cortes, lo que explica la mención en las actas de un "depositario de los fondos de esta provincia". ${ }^{62}$ A pesar de las lamentaciones del jefe político y del intendente, la depositaría de la diputación provincial, creada en septiembre de $1820,{ }^{63}$ si contaba con dinero. Casi al mismo tiempo que le comunicaba al virrey la necesidad de recursos para sostener a la tropa realista, se presentó ante la diputación provincial una cuenta con comprobantes de gastos hechos en "la habilitación de la sala de sesiones, construcción de mesas para la secretaría y sillas de ceremonia para las asistencias de esta diputación provincial". ${ }^{64}$ Así, debido a facilidades que le confirió la constitución gaditana, y aun antes de la consumación de la independencia, las corporaciones provinciales crearon su propia administración de recursos de forma paralela a lo que exigían las autoridades en la Ciudad de México.

Aunque con poca presencia del elemento militar, en el mismo tema es pertinente apuntar en dirección a otro caso de excepción que fue la diputación provincial de Yucatán. Esta corporación quedó establecida en abril de 1813. Pocas semanas después, de acuerdo con el artículo 335 , capítulo $4^{\circ}$, párrafo 3 de la constitución gaditana, se discutió sobre la necesidad de elegir a un individuo que desempeñara el encargo de depositario "para la debida seguridad de los intereses que se recauden". Para tal efecto, se nombró al "comisario ordenador honorario ministro tesorero de la hacienda nacional", que en ese tiempo era Policarpo Antonio de Echánove. ${ }^{65}$ Varios meses después, en noviembre de 1813, se nombró a

59 Acta de sesión extraordinaria 64 y 65 del 15-16 de mayo de 1821, La diputación provincial de Nueva Galicia, 2004, pp. 127-130.

60 Acta de la sesión 62 del 24 de febrero de 1821, La diputación provincial de Nueva Galicia, 2004, pp. 123-125.

61 Acta de la sesión 71 del 7 de mayo de 1821, La diputación provincial de Nueva Galicia, 2004, pp.

62 Acta de la sesión 67 del 5 de abril de 1821, La diputación provincial de Nueva Galicia, 2004, pp. XXX. Véase también "Constitución política de la monarquía española", en TEna Ramírez, Felipe, Leyes fundamentales de México, 1991, pp. 98-99.

63 Acta de la sesión 7 del 25 de septiembre de 1820, La diputación provincial de Nueva Galicia, 2004, pp. 35-36.

64 Acta de la sesión 74 del 28 de mayo de 1821, La diputación provincial de Nueva Galicia, 2004, pp. 150-153.

65 Acta de la sesión 14 del 28 de mayo de 1813, Actas de la diputación provincial de Yucatán, 2006, pp. 81-82. El cargo de Echánove era, en resumida cuenta, el tesorero de la caja de la hacienda nacional en Mérida de Yucatán. Esto significaba que ambas tesorerías eran ocupadas por el mismo personaje. Más adelante ocurrirá los mismo cuando el tesorero del estado y el comisario federal serán ocupados (temporalmente) por la misma persona. CовÁ NoH, Lorgio, “La hacienda pública en Yucatán”, 2014, pp. 66-67. 
otra persona para que desempeñara el cargo, que no contaba con remuneración alguna y que además se debía afianzar. ${ }^{66}$

El 7 de febrero de 1821, la diputación provincial yucateca recibió un oficio del recaudador de la contribución patriótica de Sotuta en el que preguntaba a quién debía entregar los productos de este ramo en la capital. La diputación le respondió que debía hacerlo al depositario provincial. El 8 de marzo de ese mismo año se hizo la propuesta que de los fondos manejados por el depositario provincial se debía extraer "lo necesario para las asistencias de los tres señores diputados que han ido a representar por esta provincia." ${ }^{\text {"67 }}$ Sobre este asunto, el 28 de marzo siguiente se discute sobre los recursos con que cuenta la diputación para enviar a sus diputados a cortes. Se habló de la pobreza de la provincia y del fuerte recargo de contribuciones que experimentaba. Parte del problema era que Yucatán desde hacía varios años ya no podía disponer de los recursos situados desde la Ciudad de México en la tesorería nacional yucateca. Y es en esta discusión que se deja claro el funcionamiento del depositario provincial frente a la caja nacional. Resulta que, en años anteriores, el situado se hallaba en esta última tesorería que, para apoyar a la provincia, le entregaba recursos, que terminaban en la caja del depositario provincial. Ante la problemática de recursos que se presentó en estos días de marzo de 1821, se propuso que los fondos de la renta de correos se quedaran en la provincia "pues no parece justo que no sólo sea socorrida la provincia por México como está mandado y antes se hacía, sino que por el contrario el corto número que circula en ella se extraiga para llevar allá". Ante esta sugerencia se acordó oficiar al intendente para que prohíba a los administradores del ramo de correos "saquen de la provincia cantidad alguna del producto de su administración y que pongan inmediatamente en poder del depositario provincial todos los productos líquidos que tengan las cajas [...]. ${ }^{68}$

El depositario de los fondos provinciales se hacía cargo de los productos de la contribución patriótica y debía informar sobre esta recaudación. Al respecto en la sesión de la diputación yucateca de 4 de abril, el depositario provincial reportaba que el subdelegado de Camino Real Alto no tenía el recurso de la contribución porque los ayuntamientos no le habían entregado lo que les correspondía. Esta situación generó un acuerdo en donde se ratificaba que "los subdelegados [debían] enterar en la tesorería de su excelencia [la diputación provincial] la contribución.”69

Lo que más destaca de la administración de las diputaciones provinciales de 1820 es que no tenían dinero. Era muy necesario en aquellos momentos de la segunda mitad de aquel año pues las nuevas corporaciones debían sufragar los sueldos de su secretario y sus asistentes. ${ }^{70}$ Además, e igualmente importante, debían

66 Acta de la sesión 37 del 29 de noviembre de 1813, Actas de la diputación provincial de Yucatán, 2006, pp. 126-128.

67 Acta de la sesión 11 del 8 de marzo de 1821, Actas de la diputación provincial de Yucatán, 2006, pp. 76-77.

68 Acta de la sesión 13 del 28 de marzo de 1821, Actas de la diputación provincial de Yucatán, 2006, pp. 79-81. Sin cursivas en el original.

69 Acta de la sesión 14 del 4 de abril de 1821, Actas de la diputación provincial de Yucatán, 2006, pp. 79-81.

70 Artículo 333 de la Constitución de 1812. En Tena Ramírez, Felipe, Leyes fundamentales de México, 1991, p. 98 . 
hacer frente a los viáticos y dietas de los diputados en las cortes. ${ }^{71}$ ¿De dónde obtendrían este recurso? La respuesta depende de cada provincia en particular.

Primeramente, en la provincia de México — que antes de noviembre de 1820 comprendía las intendencias de Veracruz, Michoacán, Querétaro, Puebla, Oaxaca, México y Tlaxcala - el cuerpo provincial se financió de los sobrantes de los recursos generados en los pueblos indígenas, que en aquellos meses de convertían en ayuntamientos constitucionales. Al respecto, Dorothy Tanck de Estrada muestra cómo, a finales del siglo anterior, los recursos de los pueblos indígenas cuyo destino era atender a sus necesidades comunitarias así como a las catástrofes, terminaron respaldando las finanzas de la monarquía. Esto se logró, dice la autora, por vía de la creación de la Contaduría General de Propios, Arbitrios y Bienes de Comunidad. El nombre de la oficina lo dice todo: una institución encargada de analizar los propios (las propiedades), los arbitrios (los impuestos) y, más importante en el caso de los pueblos indígenas, los bienes comunitarios. Este análisis perseguía el objeto de que cada pueblo — ciudad y villa, en el caso de los asentamientos españoles - elaborara su propia regla de propios, arbitrios, bienes de comunidad y gastos. La idea de la contaduría era tener información sobre los ingresos y los gastos de ciudades y pueblos; esta información se remitía anualmente para su aprobación por parte de las autoridades virreinales. ${ }^{72} \mathrm{Y}$ aunque no faltaron las críticas y resistencias, en última instancia esta política típicamente absolutista logró generar información de los sobrantes de los recursos de los pueblos, particularmente los correspondientes a los bienes de comunidad trabajados o arrendados. ${ }^{73}$

Las actas de las diputaciones provinciales del periodo constitucional restaurado en 1820 , muestran que los pueblos indígenas se habían acostumbrado a reportar sus cuentas a la contaduría. A manera de ejemplo, con objeto de conocer el monto del pago al secretario del ayuntamiento de Ixmiquilpan, el intendente de México pregunta a la diputación provincial si para este pago se podían utilizar las contribuciones generadas y que cobraba la "junta titulada de arbitrios". ${ }^{74} \mathrm{La}$ diputación aprobó el pago solicitado "para cuya paga buscará arbitrios el ayuntamiento, dando cuenta a esta superioridad". En cuanto a la junta de arbitrios - que la diputación no menciona expresamente - el asunto debía consultarse "con el superior gobierno a quien toca". ${ }^{75}$ Tenemos aquí dos temas. Por una parte el ayuntamiento se refiere a la junta de arbitrios, la creada para el financiamiento de la milicia defensora en tiempos de guerra y que es probable ya no se necesitara como antes. En segundo término, el testimonio muestra cómo la diputación provincial de México otorga permiso al ayuntamiento de Ixmiquilpan para que diseñe su propio impuesto que genere el recurso para el pago al secretario del consistorio.

71 Artículo 102 de la Constitución de 1812. En Tena Ramírez, Felipe, Leyes fundamentales de México, 1991, p. 72. Véase también, BERRY, Charles, "Elecciones para diputados", 2014 [1966], pp. 10-42.

73 Tanck de Estrada, Dorothy, Pueblos de indios, p. 130 y en general el capítulo II.

74 Véase Ortiz Escamilla, Juan, Guerra y gobierno, 2014, pp. 103-113.

75 Sesión 7a. en la Ciudad de México, a 5 de agosto de 1820, La diputación provincial de Nueva España, 2007, pp. 42-43. 
La lectura de otras actas muestra que, en su mayoría, la diputación provincial no se entendió de los impuestos creados por las juntas de arbitrios; como señala la cita anterior, el asunto era competencia de la oficina del virrey. En concreto, en julio de 1820, por vía del intendente, el ayuntamiento de Monte Bajo envía dos representaciones a la diputación de la provincia de México. Debido a que "por no ser necesario los patriotas", el cuerpo municipal solicitaba la terminación de las contribuciones sobre cargas de leña y carbón, así como la pensión militar. La respuesta de la diputación fue "que ocurra el ayuntamiento al mismo excelentísmo señor virrey, capitán general y jefe político superior, a quien tocan". ${ }^{76}$ Por otro lado, en un menor número de actas se observa que la diputación de México permitió a los ayuntamientos que generaran sus propios impuestos (arbitrios), lo que era permitido en Ultramar, según el artículo 335 fracción cuarta de la Constitución de $1812 .{ }^{77} \mathrm{Al}$ menos en los primeros meses ${ }^{78}$ esta situación no fue la más común; en cambio el cuerpo provincial permitía - no sin oposición interna- que los cabildos civiles obtuvieran sus recursos del arrendamiento o usufructo de los bienes de comunidad. ${ }^{79}$ Es lógica la reticencia de la diputación a permitir la creación de impuestos en los ayuntamientos, de ahí que frente a la solicitud de algunos para la creación de arbitrios la respuesta generalmente fuera dar largas y solicitar diagnósticos y presupuestos. A fines de noviembre de 1820, por vía del intendente de Puebla, el ayuntamiento de Xochitán solicitó a la diputación de México crear arbitrios para escuela y cárcel. El acuerdo a esta petición fue el de "no haber lugar a estos arbitrios y que el ayuntamiento espere el arreglo que por punto general queda tratando esta diputación para asignar a todos los ayuntamientos las pensiones necesarias y suficientes para sus atenciones, lo que avisarán oportunamente". ${ }^{80}$

A pesar las dificultades, no parece factible que la diputación de México estuviera totalmente carente de recursos. Recién instalada la diputación en el segundo periodo liberal, en la sesión de fines de julio de 1820, se discutieron los medios para hallar fondos que solventaran el pago de los trabajadores de esta corporación. Pocos días después, se acordó indagar en la contaduría de propios y arbitrios el estado de los fondos de los ayuntamientos "por ser sus sobrantes con los que cuenta esta diputación para las referidas pagas y demás atenciones que ocurran". ${ }^{81}$ Según Tanck de Estrada, en ese año la mayoría del dinero sobrante en 1820 fue para el gobierno; ${ }^{82}$ no sabemos cuánto de ese recurso fue a dar a la

\footnotetext{
76 Sesión 13 en la Ciudad de México, a 23 de agosto de 1820, La diputación provincial de Nueva España, 2007, pp. 60-61. Una situación similar la respondió la diputación provincial al ayuntamiento de Atlautla el 27 de febrero de 1821. Sesión 65 en la Ciudad de México, a 27 de febrero de 1821, La diputación provincial de Nueva España, 2007, p. 259.

77 Tena Ramírez, Felipe, Leyes fundamentales, 1995, p. 98.

78 Nos referimos al conjunto de sesiones de la diputación provincial de México que van del 20 de julio al 26 de septiembre de 1820. Benson, Nettie Lee, The Provincial Deputation, 2010, cap. 3.

79 TANCK De Estrada, Dorothy, Pueblos de indios 1999, p. 194, nota 82, p. 403, nota 167, pp. 567-568.

80 Sesión 39 en la Ciudad de México, del 28 de noviembre de 1820, La diputación provincial de Nueva España, 2007, pp. 142-143.

81 Sesiones 5 y 7 en la Ciudad de México del 29 de julio y 5 de agosto de 1820, La diputación provincial de Nueva España, 2007, pp. 39 y 43.

82 TancK De Estrada, Dorothy, Pueblos de indios, 1999, p. 133, cuadro 19.
} 
diputación, pero el hecho de que en sus sesiones ya no se discutiera el asunto, sugiere que en cierta medida éste se resolvió. Los referidos sobrantes se hallaban en la caja nacional de la Ciudad de México. ${ }^{83}$ No era esta, sin embargo, la única fuente de recursos de la diputación. Semanas después, el virrey enviaba a la diputación ejemplares de las cuentas de la tesorería de la Ciudad de México; el acuerdo al que se llegó fue el de revisar este documento "para que se reconozcan todas las cuentas que vinieren a esta diputación". ${ }^{84}$ Sobre esta cuestión, Gisela Moncada muestra que un año antes, en 1819, el virrey Apodaca había autorizado un convenio por el cual la aduana de la Ciudad de México administraría los fondos del ayuntamiento. La aduana entregaría los fondos mensualmente a la Contaduría de Propios y Arbitrios y ésta lo depositaría en la tesorería de la corporación municipal. ${ }^{85}$ Nos dice la misma autora que en 1820 la diputación provincial recibía estos recursos para el pago de la dieta de los diputados. ${ }^{86}$ Tal parece que en el año siguiente la diputación provincial contó con suficientes recursos como para pagar el "recibimiento de Iturbide" a la Ciudad de México. ${ }^{87}$

Ante esta evidencia se puede sugerir que desde su restablecimiento la diputación tenía más o menos resuelto su problema de recursos. Aunque no sabemos el monto al cual ascendían, la lógica nos lleva a pensar que el dinero se utilizaba tanto para el pago de las labores de la corporación como para viáticos y dietas de los diputados por la provincia de México a las cortes de Madrid y, más adelante, para otras cuestiones. En el ámbito administrativo, se debe destacar que la diputación provincial colectaba sus recursos de la tesorería de la hacienda en la Ciudad de México ( que, vale aclarar, no era la tesorería del ayuntamiento). Por esta razón, no parece que la diputación provincial de México haya atendido el artículo de la Constitución en donde se instruía que para la recaudación de los arbitrios de la diputación, ésta debía nombrar un depositario. ${ }^{88}$

\section{COMENTARIOS FINALES}

Aunque es necesario un análisis más profundo para definir el transfondo de la administrsación bobónica, los casos expuestos muestran que la adminstración

83 Sesión 62 en la Ciudad de México, a 20 de febrero 1821, La diputación provincial de Nueva España, 2007, p. 243.

84 Sesión 27 en la Ciudad de México, a17 de octubre de 1820, La diputación provincial de Nueva España, 2007, p. 103.

85 Este convenio, que seguía el espíritu conciliador de Apodaca, respondía a la necesidad de abastecer de alimentos a la Ciudad de México y evitar así sublevaciones. Moncada GonzÁlez, Gisela, "Las finanzas del ayuntamiento", 2013, pp. 9-14

86 Moncada GonzÁLez, Gisela, "La fiscalidad en el ayuntamiento”, 2011, pp. 135-136 nota 15. Se refiere a la dieta de los diputados en las cortes y no los diputados de la corporación provincial, pues éstos debían tener sus propios medios para sostenerse. Artículo 330 de la Constitución de 1812, en Tena Ramírez, Felipe, Leyes fundamentales de México, 1997, p. 98.

87 Moncada GonzÁLEz, Gisela, "Las finanzas del ayuntamiento", 2013, p. 24, nota 32. Al respecto, véase también Rodríguez O., Jaime E., "La transición de colonia", 1993, p. 310.

88 Artículo 335 fracción cuarta de la Constitución de 1812, en TenA RAmírez, Felipe, Leyes fundamentales de México, 1991, p. 98. 
fiscal de la Real Hacienda experimentó pérdida de rutinas y conocimiento acumulado. No podía ser de otra manera; los mandos político y militar se unieron porque este último no podía esperar a que el pago y abasto a la oficialía y tropa se detuvieran. De ahí que la formación de juntas para determinar arbitrios, tanto a nivel de los pueblos, villas, ciudad y la propia administración general del virreinato decidiera nó sólo la creación de nuevas figuras de ingreso fiscal, sino también de oficinas de reciente creación que se adecuaran a la realidad.

Lo que también se sugiere es que los funcionarios menores de la administración debieron enfrentarse a una situación inusitada que los llevó a huir de sus cargos. Esto resulta tanto por el miedo como por la conveniencia, así como para no pagar lo confiscado, sin comprobantes, por los militares o para evadir un trabajo difícil y probablemente mal pagado. Por otra parte, tanto los intendentes como el alto mando quedaron con modificaciones en las oficinas de la Ciudad de México aunque es probable que también experimentaran el desorden por la situación en sí y por el cambio continuo de reglas y procedimientos.

La llegada desde España de los expedicionarios militares pacificó algunas regiones del territorio. En 1816 llegó el virrey Apodaca y aplicó indultos que prometían la eliminación de contribuciones arbitrarias. Algunas promesas no se cumplieron, pero la restauración de la constitución liberal permitió la formación de instituciones representativas que pronto se percataron de las peticiones de las comunidades formadas en ayuntamientos electos. No se logró con los objetivos de manera que los intentos de Apodaca que, si bien tuvieron algún éxito en términos de restauración del orden administrativo, se vinieron abajo con el movimiento trigarante dirigido por Agustín de Iturbide. A partir de ese momento México inició un nuevo periodo con un fuerte elemento militar al mando de grandes porciones del territorio y con una administración financiera pública desarticulada y sin sistema.

\section{BIBLIOGRAFÍA}

Archivos

AHH Archivo General de la Nación México

AHH Archivo Histórico de Hacienda

\section{Hemerografía}

Gaceta de México, Ciudad de México.

\section{Fuentes consultadas}

AnnA, Timothy E., "The Last Viceeroys of New Spain and Peru: An Appraisal",

The American Historical Review, vol. 81:1, febrero de 1976, pp. 38-65. Archer, Christon I., The Army in Bourbon Mexico, 1760-1810, Albuquerque, University of New Mexico Press, 1977. 
ArCHER, Christon I., "Soldados en la escena continentas: los expedicionarios españoles y la guerra de la Nueva España, 1810-1825”, en OrTIZ EsCAMILLA Juan, (coordinador), Fuerzas militares en Iberoamérica, siglos XVIII y XIX, México, El Colegio de México/El Colegio de Michoacán/Universidad Veracruzana, 2005, pp. 139-156.

Archivo General de la Nación México, Documentos para la historia de la guerra de independencia, 1810-1821, 3 volúemenes, México, Imprenta de Manuel León Sánchez, 1923.

Arnold, Linda, La secretaría de cámara del virreinato en México, México, Archivo General de la Nación, 1979.

BARragán Barragán, José, Introducción al federalismo. La formación de los poderes, 1824, México, UNAM, 1978.

Benson, Nettie Lee, The Provincial Deputation in Mexico. Harbinger of Provincial Autonomy, Independence and Federalism, Austin, University of Texas Press, 2010 [1955].

BERry, Charles, "Elecciones para diputados mexicanos a las cortes españolas, (1810-1822), en Benson, Nettie Lee, (coordinadora), México y las Cortes españolas, (1810-1822). Ocho ensayos, México, Tribunal Federal Electoral del Poder Judicial de la Federación, 2014 [1966].

CoвA NoH, Lorgio, "La hacienda pública en Yucatán: las vicisitudes del erario nacional y estatal, 1810-1839", Tesis de doctorado en Historia Moderna y Contemporánea, Instituto Mora, 2014.

EsPinosa Aguirre, Joaquín Edgardo, "Los abusos de la oficialidad contrainsurgente durante los años de la guerra de independencia", Tesis de Licenciatura en Historia, UNAM/Facultad de Filosofía y Letras/Colegio de Historia, 2015.

Folsom, Bradley, Arredondo. Last Spanish Ruler of Texas and Northeastern New Spain, Norman, University of Oklahoma Press, 2017.

Galván Hernández, José Luis, "La voz de la jurisdicción real. La fiscalía de real hacienda de Nueva España, 1781-1821”, Tesis de Maestría en Historia Moderna y Contemporánea, Instituto Mora, 2020.

IBARRA Romero, Antonio, "Marcado urbano y mercado regional en Gudalajara colonial, 1770-1810", Tesis de doctorado en Historia, Centro de Estudios Históricos, El Colegio de México, 2000.

JÁUREGUI, Luis, La real hacienda de Nueva España. Su administración en la época de los intendentes, México, UNAM-Facultad de Economía, 1999.

JÁUREGUI, Luis, "Nueva España y la propuesta administrativo-fiscal de las Cortes de Cádiz”, en Virginia GuedeA, (coordinadora), La independencia de México y el proceso autonomista novohispano, 1808-1824, México, UNAM-IIH/ Instituto Mora, 2001, pp. 83-116.

JÁUREGUI, Luis, "Una visión particular del tránsito de la administración del erario novohispano al nacional: el caso del alcabalatorio de Chautla", IBARRA, Ana Carolina; ORTIZ 
Escamilla, Juan y Tecuanhuey, Alicia, (Coord.), Herrejón. Legado sobre la independencia mexicana, México, Universidad Veracruzana/Universidad Nacional Autónoma de México/Benemérita Universidad Autónoma de Puebla/El Colegio de Michoacán, 2021, pp.

La diputación provincial de Nueva Galicia. Actas de sesiones, 1820-1822, México, Instituto Mora/Universidad de Guadalajara, 2004.

La diputación provincial de Yucatán. Actas de sesiones, 1813-1814, 1820-1821, México, Instituto Mora, 2006.

La diputación provincial de Nueva España. Actas de sesiones, 1820-1821, Segunda Edición, México, Instituto Mora/El Colegio Mexiquense/El Colegio de Michocán, 2007

MÉndez PÉRez, Juan Ramón, “La quiebra del Tribunal de Minería de la Nueva

España vista mediante el financiamiento a las actividades bélicas de la Corona española, y su herencia a la deuda pública mexicana", Revista Mexicana de Historia del Derecho, 2012, vol. XXvi, pp. 25-68.

Moncada González, Gisela, "Las finanzas del ayuntamiento de la Ciudad de

México, 1820-1855: un balance positivo", en Estudios de Historia Moderna

y Contemporánea, vol 45:1, enero-junio de 2013, pp. 3-29.

Moreno Gutiérrez, Rodrigo, La trigarancia. Fuerzas armadas en la consumación de la independencia, Nueva España, 1820-1821, México, UNAM-IIH/ Fideicomiso Felipe Teixidor y Monserrat Alfau de Teixidor, 2016.

Moreno Gutiérrez, Rodrigo, "Intendentes e independencia. Militarización y control regional en la revolución de Nueva España”, en O’PHELAN Godor, Scarlett y IBARRA, Ana Carolina, (compiladoras), Territorialidad y poder regional de las intendencias en las independencias de México y Perú, Lima, Fondo Editorial del Congreso de Perú, 2019, pp. 345-382.

Ortiz Escamilla, Juan, Guerra y gobierno. Los pueblos y la independencia de México (1808-1823, segunda edición corregida y aumentada, México, Instituto Mora/El Colegio de México, 2016.

Pietschmann, Horst, Las reformas borbónicas y el sistema de intendencias en Nueva España. Un estudio político administrativo, México, Fondo de Cultura Económica, 1996, [1972].

Pietschmann, Horst, "Las múltiples dimensionas históricas de las reformas fiscales en la Nueva España del siglo XVIII", en BERTrand, Michel y MoutouKIAS, Zacharías, (editores), Cambio institucional y fiscalidad. Mundo hispánico, 1760-1850, Madrid, Casa de Velázquez, pp. 65-90.

Rodríguez O., Jaime E., "La transición de colonia a nación: Nueva España, 1820-1821", en Historia Mexicana, vol. 43:2, 1993, pp. 265-322.

SÁnchez SANTIRÓ, Ernest, "La hacienda reformada: la centralización de la renta de alcabalas en Nueva España (1754-1781)" en SÁnchez SANTIRó, Ernest; JÁuREGUI, Luis e IbARRA, Antonio, (coordinadores), Finanzas y política en el mundo iberoamericano. Del antiguo régimen a las naciones independientes, México, Universidad Autónoma de Morelos/Instituto Mora/UNAMFacultad de Economía, 2001, pp. 143-177. 
SÁnchez SANTIRó, Ernest, "Igualas producción y mercado: las alcabalas novohispanas en la receptoría de Cuautla de Amilpas (1776-1821), en Secuencia, número 49, enero 2001, pp. 6-41.

SÁNCHEZ SANTIRó, Ernest, Las alcabalas mexicanas (1821-1857). Los dilemas en la construcción de la hacienda nacional, México, Instituto Mora, 2009.

SÁNCHEz SANTIRó, Ernest, "Guerra y restauración del antiguo régimen fiscal en Nueva España. La junta menor de arbitrios de 1815", en Jahrbuch für Geschichte Lateinamerikas = Anuario de Historia de América Latina, núm. 48, 2011, pp. 57-81.

SÁNCHEZ SANTIRÓ, Ernest, "Genealogía, contenido y consecuencias de un documento contable: las Relaciones de valores y distribución de la real hacienda de Nueva España en el quinquenio de 1744 a 1748", en Relaciones de valores y distribución de la real hacienda de Nueva España, 1744-1748, México, Instituto Mora/Archivo General de la Nación/El Colegio de Michoacán/ El Colegio de San Luis, 2014, pp. 15-59.

SÁnchez SANTIRó, Ernest, La imperiosa necesidad. Crisis y colapso del erario de Nueva España (1808-1821), México, Instituto Mora/El Colegio de Michoacán, 2016.

SÁNCHEZ SANTIRÓ, Ernest, "El aprovisionamiento de las fuerzas de defensa continental del reino de Nueva España y sus provincias adyacentes: el caso del sistema de habilitados castrenses", en ToRres SÁNCHEZ, Rafael, (coordinador), Studium, magisterium et amicitia. Homenaje al profesor Agustín González Enciso, Pamplona, Ediciones Eunate, 2018, pp. 361-368.

SÁNCHEZ SANTIRÓ, Ernest, “Ordenar las cuentas". La reforma contable de Tomás Ortiz de Landazuri (1766-1767) y su aplicación en la real hacienda de Nueva España", en Celaya NÁNDEZ, Yovana y SÁNchez SANTiRó, Ernest, (coordinadores), Hacienda e instituciones. Los erarios region, eclesiástico y municipal en Nueva España: coexistencia e interrelaciones, México, Instituto Mora/Universidad Veracruzana, 2019, pp. 129-172.

SÁnchez SANTIRó, Ernest, "La reforma de los mecanismos de control en la real hacienda de Nueva España, (siglos XVI-XVII)", en Anuario de Estudios Americanos, vol. 76:1, pp. 209-236.

Serrano Ortega, José Antonio, "Cadiz Liberalism and Public Finances: Direct Contributions in Mexico, 1810-1835", en Jaime E. Rodríguez O., (editor), The Divine Charter. Constitutionalism and Liberalism in Nineteenth Century Mexico, Lanham, Rowman \& Littlefield Publishers, 2005, pp. 255-285.

Serrano Ortega, José Antonio, Igualdad, uniformidad, proporcionalidad. Contribuciones directas y reformas fiscales en México, 1810-1846, México, Instituto Mora/El Colegio de Michoacán, 2007.

TANCK De Estrada, Dorothy, Pueblos de indios y educación en el México colonial, 1750-1821, México, El Colegio de México, 1999.

Tena Ramírez, Felipe, Leyes fundamentales de México, 1808-1991, México, Editorial Porrúa, 1991. 
Valle Pavón, Guillermina del, "El consulado de comerciantes de la Ciudad de México y las finanzas novohispanas, 1592-1827”, Tesis de doctorado en Historia, Centro de Estudios Históricos, El Colegio de México, 1997.

Vizcaya Canales, Isidro, En los albores de la independencia. Las Provincias Internas de Oriente durante la insurrección de don Miguel Hidalgo y Costilla, 1810, Monterrey, ITESM, 1976.

Von Wobeser, Gisela, Dominación colonial. La consolidación de vales reales en Nueva España, 1804-1812, México, UNAM/IIH, 2014.

Esta obra está bajo licencia internacional Creative Commons ReconocimientoNo-Comercial-CompartirIgual 4.0.

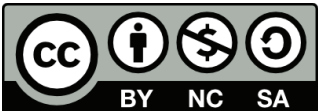

